\title{
G Protein-Coupled Receptor 30 Mediates the Anticancer Effects Induced by Eicosapentaenoic Acid in Ovarian Cancer Cells
}

Yue Zhao, PhD'
Meng-Fei Zhao, BS
Mei-Lin Yang, PhD²
Tian-Yu Wu, BS'
Cong-Jian Xu, PhD ${ }^{3}$
Jing-Mei Wang, PhD'
Chao-Jun Li, PhD'
Xi Li, PhD

${ }^{*}$ A list of author's affiliations appears at the end of the paper.

Correspondence: Yue Zhao, $\mathrm{PhD}$

State Key Laboratory of Pharmaceutical Biotechnology and Jiangsu Key Laboratory of Molecular Medicine, Medical School of Nanjing University, Nanjing 210093, China Tel: 86-02583596845

Fax: 86-02583596845

E-mail: zhyue@nju.edu.cn

Co-correspondence: Chao-Jun $\mathrm{Li}, \mathrm{PhD}$ State Key Laboratory of Pharmaceutical Biotechnology and Jiangsu Key Laboratory of Molecular Medicine, Medical School of Nanjing University, Nanjing 210093, China Tel: 86-02583596289

Fax: 86-02583596289

E-mail: licj@nju.edu.cn

Co-correspondence: $\mathrm{Xi} \mathrm{Li}, \mathrm{PhD}$

Biology Science Institutes, Chongqing Medical University, Yuzhong, China

Tel: 86-02363664840

Fax: 86-02363664840

E-mail: lixi@shmu.edu.cn

Received July 7, 2019

Accepted March 3, 2020

Published Online March 5, 2020

*Yue Zhao, Meng-Fei Zhao, and Mei-Lin Yang contributed equally to this work.

\section{Purpose}

While numerous epidemiological studies have indicated that omega-3 polyunsaturated fatty acids have anticancer properties in various cancers, the effects and mechanisms of eicosapentaenoic acid (EPA) in ovarian cancer cell growth are poorly understood.

\section{Materials and Methods}

ES2 ovarian clear cell carcinoma cells and SKOV3 adenocarcinoma cells were treated with palmitic acid or EPA, followed by flow cytometry and cell counting to measure apoptosis and proliferation, respectively. A modified protein lipid overlay assay was used to further verify whether EPA was a ligand of G protein-coupled receptor 30 (GPR30) in ES2 cells. The levels of apoptosis-related genes, phosphorylated AKT, and phosphorylated ERK1/2 were detected to explore the underlying mechanism. Finally, inhibitory effect of EPA on tumor growth via GPR30 was determined in vitro and in vivo.

\section{Results}

EPA suppressed ES2 ovarian clear cell carcinoma cells growth via GPR30, a novel EPA receptor, by inducing apoptosis. As a ligand of GPR30, EPA activated the GPR30-cAMPprotein kinase A signaling pathway. When GPR30 was suppressed by siRNA or its inhibitor G15, the antiproliferative action of EPA was impaired. Furthermore, EPA inhibited tumor growth by blocking the activation of AKT and ERK. In the mouse xenograft model, EPA decreased tumor volume and weight through GPR30 by blocking tumor cell proliferation.

\section{Conclusion}

These results confirm that EPA is a tumor suppressor in human ovarian clear cell carcinoma cells and functions through a novel fatty acid receptor, GPR30, indicating a mechanistic linkage between omega-3 fatty acids and cancers.

\section{Key words}

Eicosapentaenoic acid, GPR30, Ovarian neoplasms, Cell proliferation 


\section{Introduction}

The study of the association between diet and human cancer has drawn considerable attention in recent decades, especially which and how dietary factors might influence cancer risk. The new concept that changing diet can alter the epigenetic state of genes, thereby increasing or decreasing cancer risk, has been put forth in recent years [1]. Epidemiological studies have indicated a connection between various fatty acids (FAs) and ovarian cancer risk [1]. It has been reported that polyunsaturated fatty acids (PUFAs) can generate several omega-3 lipid metabolites and inhibit omega- 6 arachidonic acid production, thus playing a beneficial role [2]. Previous study has shown the benefit of the omega-3 FAs on breast cancer incidence [3], but little information exists on the effects and mechanisms of eicosapentaenoic acid (EPA) in ovarian cancer cell growth.

Ovarian cancer is the most fatal gynecologic malignancy worldwide [4]. It is mostly detected at an advanced stage, leading to a high mortality rate. The pathogenesis of ovarian cancer has long been investigated but is still poorly understood. Obviously, it is urgent to optimize or develop new therapeutic strategies in the management of this disease. EPA, one kind of omega-3 polyunsaturated FA, has been observed to be significantly lower in the plasma of patients with any of several cancers than in the plasma of healthy individuals [4], implying its considerable role in cancer development. Several studies have suggested that EPA inhibits ovarian cancer cell growth and suppresses tumor metastasis [5].

Compelling evidence shows that FAs could achieve their biological effect by governing the fluidity and configuration of membrane receptors, cell signaling pathways, transcription of genes, and inflammatory response [6]. In recent years, many studies have described and characterized several $G$ protein-coupled receptors (GPRs) for FAs in cancer cells, which have been reported to be critical components of the sensing apparatus in the human body and to have specificities for FAs of differing saturation degrees and chain lengths. Free fatty acid receptor 1 (GPR40) and GPR120, which both have $\mathrm{G} \alpha \mathrm{q} / 11$ as their $\mathrm{G} \alpha$ subunit, are receptors for long-chain unsaturated FAs. GPR30, another novel FA receptor, is a 7-transmembrane estrogen receptor of the Gas family predominantly localized in the endoplasmic reticulum. Many steroids and some synthetic estrogen-receptor ligands function by binding to GPR30 [7]. Once bound, the production of cyclic AMP (cAMP) was promoted, causing epidermal growth factor cleavage and epidermal growth factor receptor transactivation [7]. GPR30 is expressed not only in normal tissues, including the uterus, ovaries, and mammary glands, but also in several cancers, including ovarian cancer, in which GPR30 is highly expressed and correlated with a poor prognosis [8].

In this study, we found that EPA suppressed ES2 ovarian clear cell carcinoma (OCCC) cells growth through GPR30 by activating caspase-3 and inducing apoptosis. Furthermore, GPR30 was expressed in patients with various ovarian cancers, and $300 \mu \mathrm{M}$ EPA suppressed human ovarian cancer cell growth via GPR30 without influencing normal cells. All these findings open a new front in the battle against ovarian cancer.

\section{Materials and Methods}

\section{Materials}

FAs, FA-free bovine serum albumin (BSA), and forskolin were purchased from Sigma-Aldrich (St. Louis, MO). Fura2/ AM was purchased from Dojindo (Kumamoto, Japan). G1 and G15 were purchased from TOCRIS Bioscience (Ellisville, MI) and Merck (San Diego, CA), respectively. YM254890 was from Yama-nouchi Pharmaceutical Co., Ltd. (Ibaraki, Japan).

\section{Cell lines and culture}

ES2 and SKOV3 cell lines were obtained from the American Type Culture Collection (ATCC). ES2 and SKOV3 cells were cultured in McCoy's 5A medium supplemented with $10 \%$ fetal bovine serum and antibiotics. Cells were cultured in Opti-MEM (Gibco, Grand Island, NY) without fetal bovine serum. FAs were first dissolved in pure ethanol and then freshly diluted to the culture medium containing $1 \%$ BSA. The ethanol and BSA were $0.05 \%(\mathrm{v} / \mathrm{v})$ and $0.1 \%(\mathrm{v} / \mathrm{v})$, respectively.

\section{Cell proliferation assay and cytotoxicity assay}

For the assay of ES2 and SKOV3 cell proliferation, $5 \times 10^{3}$ cells per well in Opti-MEM with different types and concentrations of FAs were seeded in triplicate, and cell numbers were monitored after 24, 48, and 72 hours using the Cell Counting Kit-8 (Dojindo). The cytotoxicity of various FAs at different concentrations on ES2 and SKOV3 cells was measured with the Cytotoxicity LDH Assay Kit-WST (Dojindo). All experiments were performed in triplicate wells for each condition and repeated three times independently. 


\section{Cell apoptosis assay}

A total of $0.5 \times 10^{6}$ cells were cultured into 6-well culture plates and cocultured with or without $300 \mu \mathrm{M}$ EPA for 48 hours. For cell apoptosis analysis, cells were determined with the Annexin V/PI Apoptosis Detection Kit (Dojindo) and analyzed by a FACSCalibur (BD Bioscience, San Jose, CA).

\section{Cytosolic calcium determination}

Cells were trypsinized in 3.5-cm Petri dishes, centrifuged, and resuspended in phosphate buffered saline (PBS) with 3 $\mathrm{mM}$ Fura-2/AM. Cells were treated with the $\mathrm{Ca}^{2+}$ indicator Fura-2/ AM ( $5 \mu \mathrm{M})$ to measure $\left[\mathrm{Ca}^{2+}\right]$ i. After washed for three times to remove extracellular Fura-2/AM, the Fura-2 was detected using Felix fluorescence data acquisition as previously shown [9]. The dose of YM254890 was based on previous findings $[10,11]$.

\section{6. cAMP measurement}

Cells were seeded and treated with G15 or GPR30 small interfering RNA (siRNA). The dose of G15 was based on Wang et al. [12] and Bai et al. [13], who found that the $8 \mu \mathrm{M}$ dose would be sufficient to obtain antagonistic effects on GPER1 / GPR30 without affinity for other estrogen receptors. Twenty-four hours later, the cells were seeded in Opti-MEM medium for 5 hours and then treated with BSA, palmitic acid, or EPA. Cells were washed with PBS twice and frozen and thawed three times after treatment. The cAMPs were quantified with an Enzyme Immunoassay Kit (Cayman Chemical, Ann Arbor, MI).

\section{Lipid-protein overlay assay}

The nitrocellulose membrane was spotted with EPA (1, 3, and $5 \mathrm{mM}$ ) and then blocked in buffer as previously reported [14]. Next, the membrane was incubated with purified GFPGPR30 protein $(100,200$, and $400 \mathrm{ng} / \mathrm{mL})$ overnight at $4^{\circ} \mathrm{C}$, then scanned by Typhoon FLA9500 (GE Healthcare, Uppsala, Sweden) to detect GFP.

\section{Ovarian cancer xenograft models}

Ovarian cancer xenograft models were generated in old female nude mice at 4 to 6 weeks of age by injecting $1 \times 10^{7}$ ES2 cells treated with or without adenoviral GPR30 shRNA into subcutaneous fat. Animals were divided into four groups with 10 per group. For the experimental group, $10 \mu \mathrm{L}$ EPA was added to $90 \mu \mathrm{L}$ aqueous vehicle. For the control group, $10 \mu \mathrm{L}$ ethanol was added to $90 \mu \mathrm{L}$ aqueous vehicle. Mice were given EPA $(4 \mu \mathrm{g})$ once daily. For the treatment of
G15, ovarian cancer xenograft models were generated in old female nude mice at 4 to 6 weeks of age by injecting $1 \times 10^{7}$ ES2 cells into subcutaneous fat. Animals were divided into four groups with 10 per group. Nude mice bearing ovarian tumors were received dimethyl sulfoxide (DMSO) in combination with $\mathrm{MeOH}$ as a control, EPA in combination with DMSO, MeOH in combination with G15 or EPA in combination with G15. Mice were given EPA (4 $\mu \mathrm{g}$ ) once daily, while G15 $(10 \mu \mathrm{g})$ once daily from day 5 . Tumor volumes were calculated as $1 / 2 \times$ length $\times$ width ${ }^{2}$. Ki67 and GPR30 were stained to assay the inhibitory effects of EPA and GPR30 expression, respectively.

\section{Tissue microarray construction and immunohistochem- ical analysis}

Ovarian cancer patient $(n=173)$ samples were collected from the Department of Pathology of Nanjing Drum Tower Hospital. The tissue microarray (TMA) was made as previously reported [15]. The immunohistochemical stains were assessed by three separate observers who did not know patient characteristics. The classification of GPR30 expression level was based on the staining intensity of GPR30. All protocols for humans were reviewed and approved (kyy201538). The detailed information of TMA was provided in S1-S3 Tables.

\section{Quantitative real-time PCR}

Quantitative real-time PCR was performed using SYBR Select Master Mix (Vazyme, Nanjing, China) in an ABI 7300 sequence detector. The results were normalized to the $18 \mathrm{~S}$ rRNA gene expression level in each sample. The primers were from PrimerBank (http://pga.mgh.harvard.edu/primerbank/).

\section{Antibodies and immunoblotting}

The antibodies used were cleaved caspase-3, AKT, p-AKT, ERK, p-ERK, phosphorylated protein kinase A (p-PKA) substrate (Cell Signaling Technology, Danvers, MA), actin (Sigma-Aldrich), and GPR30 (Santa Cruz Biotechnology, Santa Cruz, CA).

\section{RNA interference}

The siRNA against GPR30 was GCACCUGUGGCUGACGAAUUU. ES2 cells were transfected with RNA interference (RNAi) oligonucleotides using Lipofectamine RNAiMAX (Invitrogen, Carlsbad, CA). 

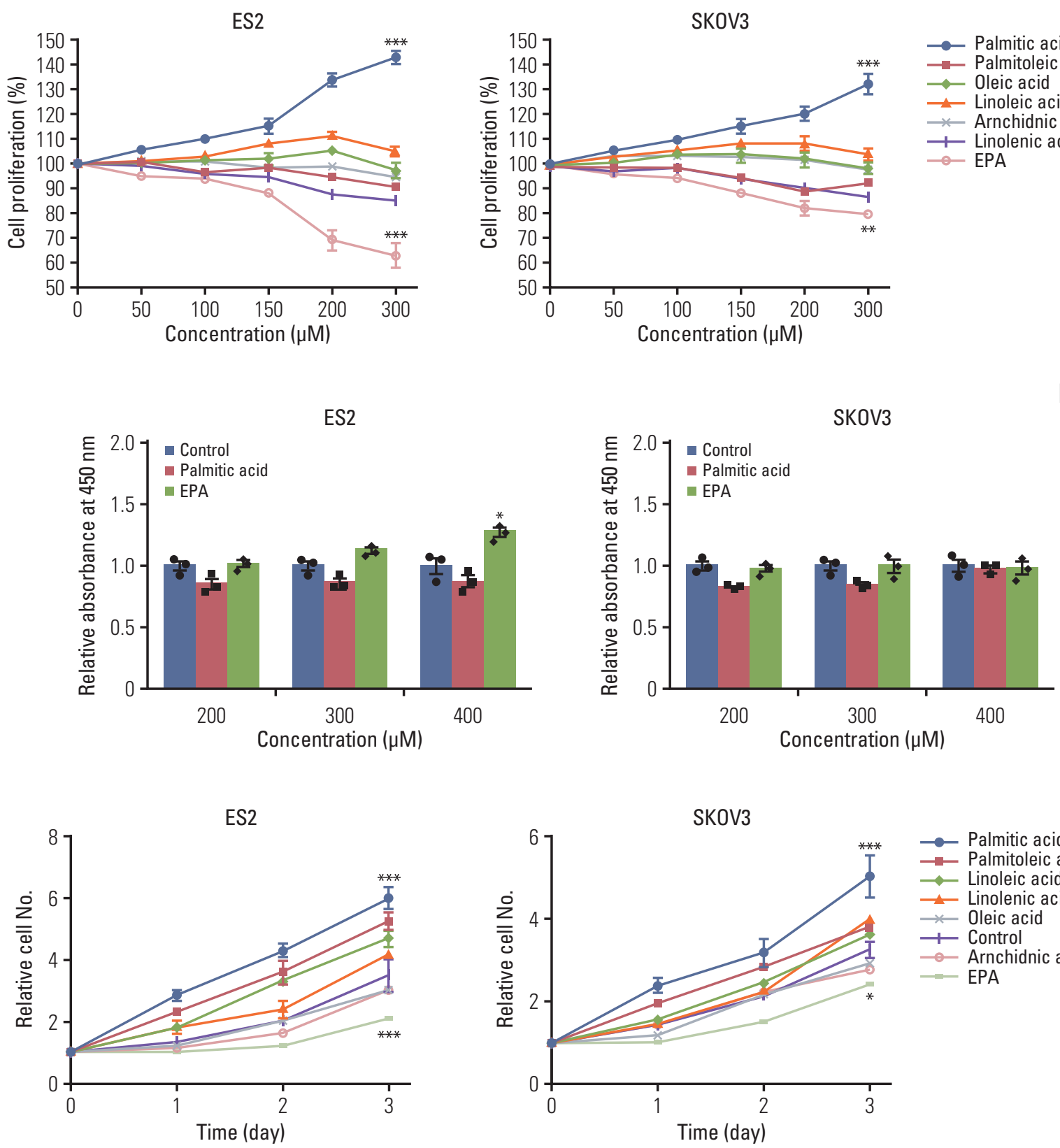

C

Fig. 1. Eicosapentaenoic acid (EPA) inhibits cell proliferation in ovarian cancer cells. (A) Dose-response curves of palmitic acid, palmitoleic acid, oleic acid, linoleic acid, arachidonic acid, linolenic acid, and EPA in ES2 cells and SKOV3 cells. (B) The toxicity of palmitic acid and EPA at different concentrations on ES2 and SKOV3 cells. (C) Cell proliferation of ES2 and SKOV3 cells in time course for various fatty acids in ES2 cells and SKOV3 cells were treated with $300 \mu \mathrm{M}$ fatty acids. (Continued to the next page)

\section{Adenoviral expression vectors}

The GPR30 shRNA sequence was GCACCTGTGGCTGACGAATTT. Adenovirus was amplified and purified using Sartorius Adenovirus Purification kits (Sartorius, Germany).

\section{Statistics}

Data from at least three independent experiments were analyzed and are expressed as means \pm standard deviation. The nonpaired Student's $t$ test was used for these analyses. A difference was considered significant at $\mathrm{p}<0.05, \mathrm{p}<0.01$, 

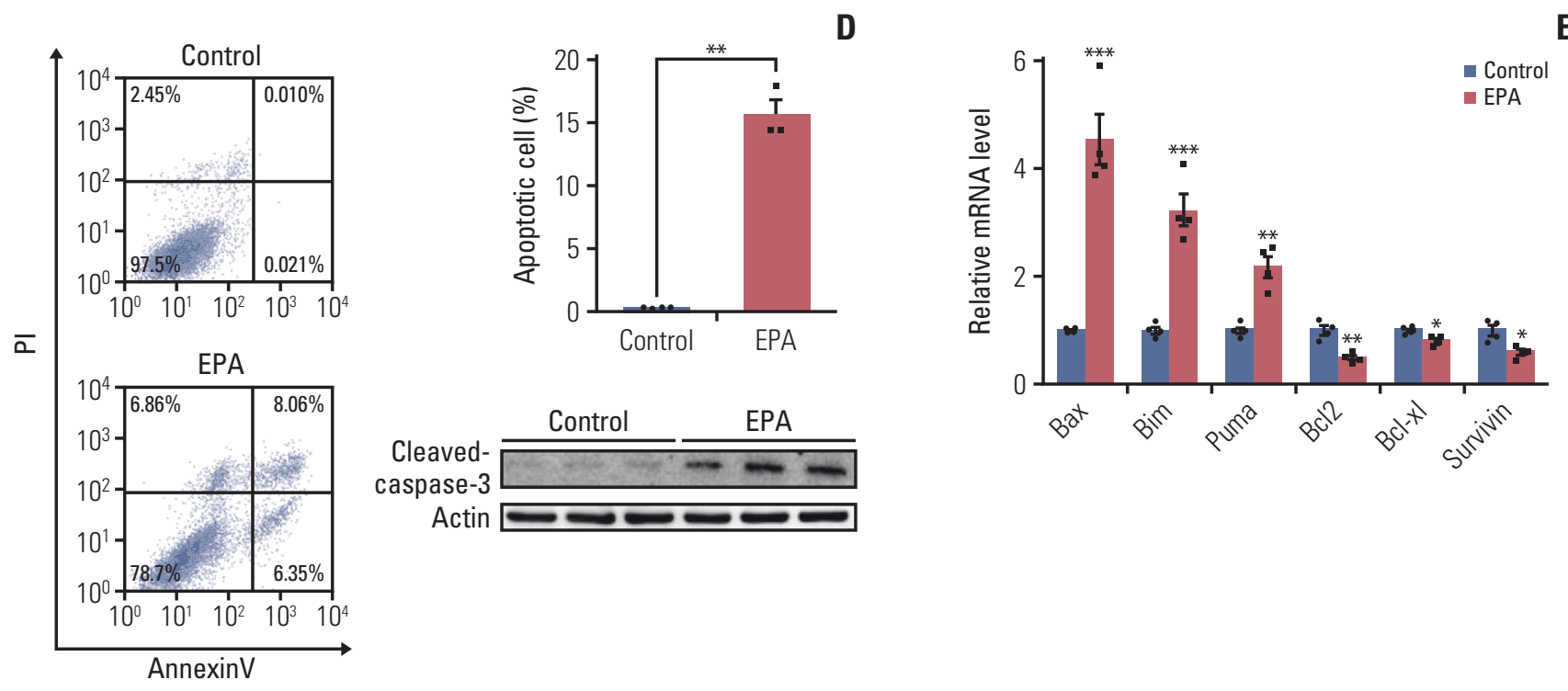

$\mathbf{F}$
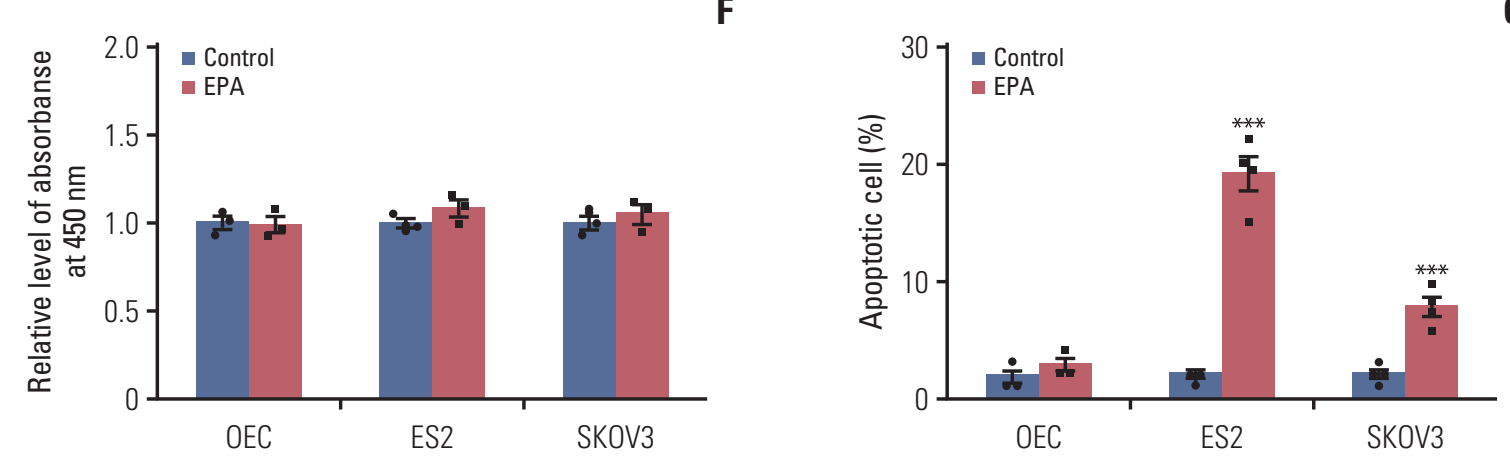

Fig. 1. (Continued from the previous page) (D) Apoptosis by EPA in ES2 cells. The cells were treated with or without $300 \mu \mathrm{M}$ EPA for 48 hours. Apoptosis was detected by cleaved caspase-3. PI, propidium iodide. (E) The expression of proapoptotic genes and antiapoptotic genes in ES2 cells treated with or without $300 \mu \mathrm{M}$ EPA for 48 hours was analyzed by quantitative reverse transcription polymerase chain reaction. (F) The toxicity of EPA on normal ovarian epithelial cells (OEC), ES2, and SKOV3 cells. (G) The apoptosis rate of normal OEC, ES2, and SKOV3 cells treated with EPA. Values are presented as mean \pm standard deviation from three independent experiments. ${ }^{*} p<0.05,{ }^{* *} p<0.01,{ }^{* * *} p<0.001$.

and $\mathrm{p}<0.001$. $\mathrm{R}$ was used for the correlation analysis of GPR30 expression level with overall survival of ovarian cancers patients. Then packages "survival" and "survminer" were used for survival analysis using Kaplan-Meier method and generate the survival curve.

\section{Ethical statement}

All animal procedures were carried out in accordance with the approval of the Animal Care (\#CS20) and Use Committee at the Model Animal Research Center of Nanjing University in Nanjing.

\section{Results}

\section{EPA inhibits cell proliferation in ovarian cancer cells}

FAs have an effect on cancer by altering cell membrane synthesis and saturation and via cholesterol lipid hormones that affect the function and distribution of signaling macromolecules [6]. Thus, we speculated that various FA treatments might influence different aspects of cancer development in ovarian cancer cells. Ovarian carcinoma is divided into four major histological types: clear cell, mucinous, serous, and endometrioid [16]. OCCCs makes up 25\% of ovarian car- 


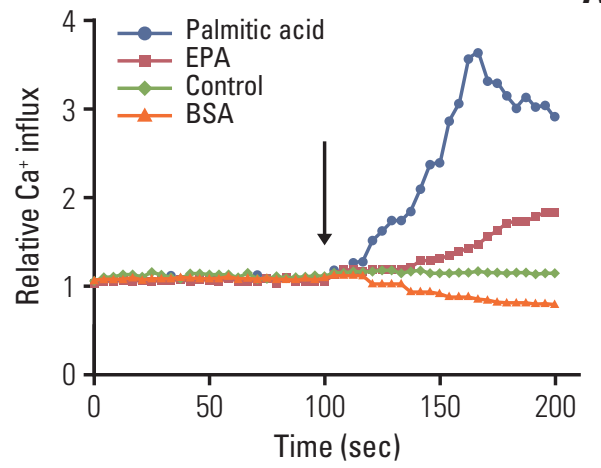

A

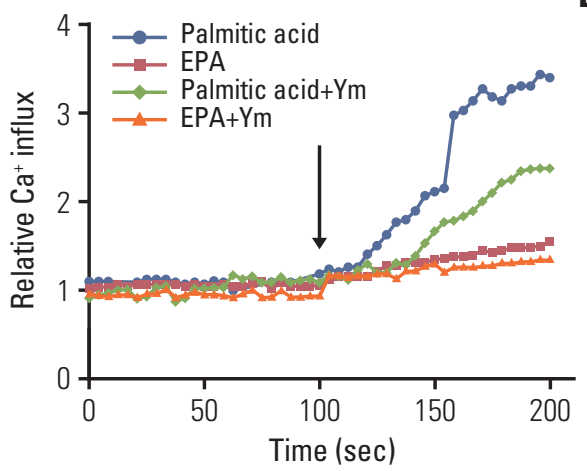

C

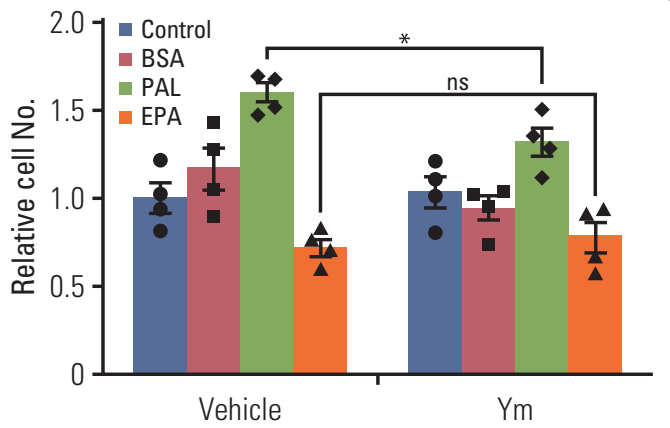

D

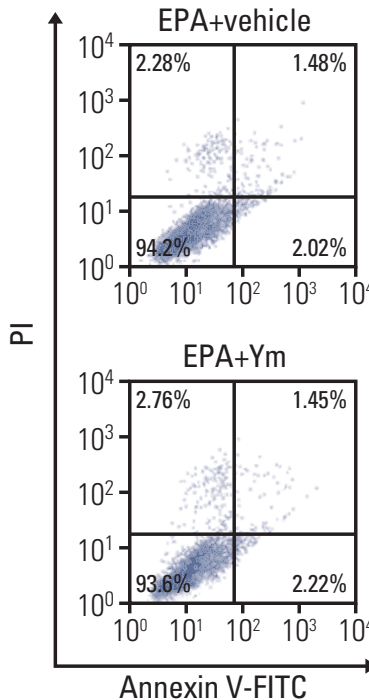

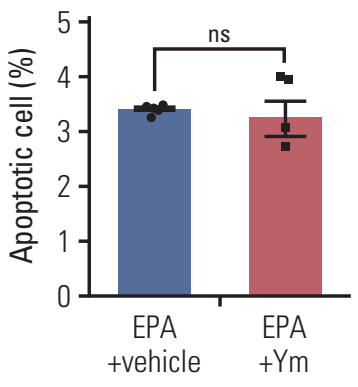

EPA+vehicle EPA+Ym

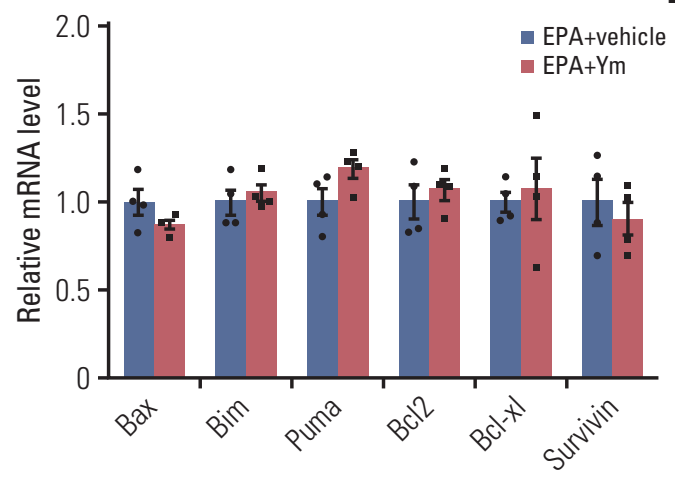

Fig. 2. G protein-coupled receptor 30 (GPR30) acts as a novel eicosapentaenoic acid (EPA) receptor in ES2 cells. (A, B) ES2 cells were loaded with $3 \mu \mathrm{M}$ of the fluorescent calcium probe fura-2A/M. (A) Cells were stimulated in phosphate buffered saline alone (control), $300 \mu \mathrm{M}$ palmitic acid bound to bovine serum albumin (BSA) $(0.1 \%), 300 \mu \mathrm{M}$ EPA bound to BSA $(0.1 \%)$, or BSA alone. (B) ES2 cells were incubated with YM254890 (Gq protein inhibitor) at $37^{\circ} \mathrm{C}$ for 5 minutes before the addition of fatty acids. The arrows indicate the onset of stimulation. (C) Cell proliferation of ES2 cells treated with $0.1 \%$ BSA, $300 \mu \mathrm{M}$ palmitic acid (PAL), or $300 \mu \mathrm{M}$ EPA in the absence or presence of YM254890 for 24 hours. (D) Apoptosis of ES2 cells treated with $300 \mu \mathrm{M}$ EPA in the absence or presence of YM254890. Apoptosis was detected by cleaved caspase-3. PI, propidium iodide. (E) The expression of proapoptotic genes and antiapoptotic genes in ES2 cells treated with $300 \mu \mathrm{M}$ EPA in the absence or presence of YM254890 for 48 hours was analyzed by quantitative reverse transcription polymerase chain reaction (RTPCR). (Continued to the next page) 
$\mathbf{F}$

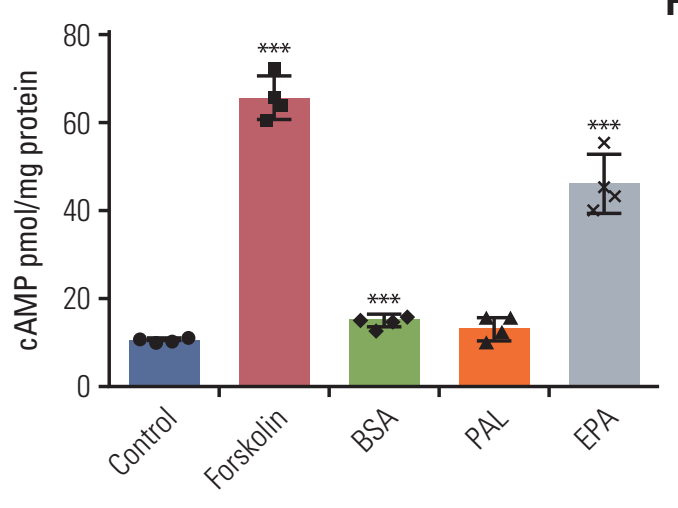

H

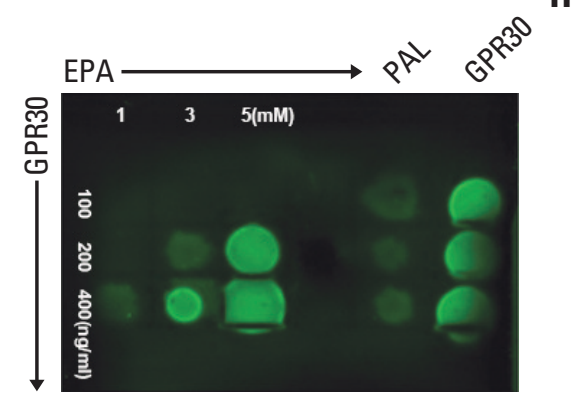

G

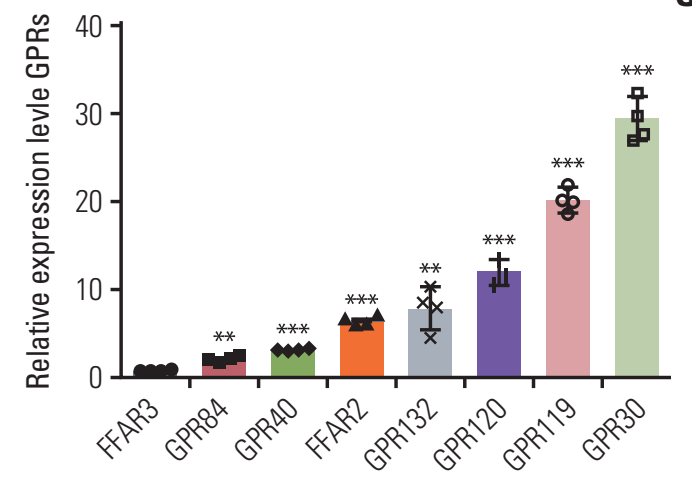

I

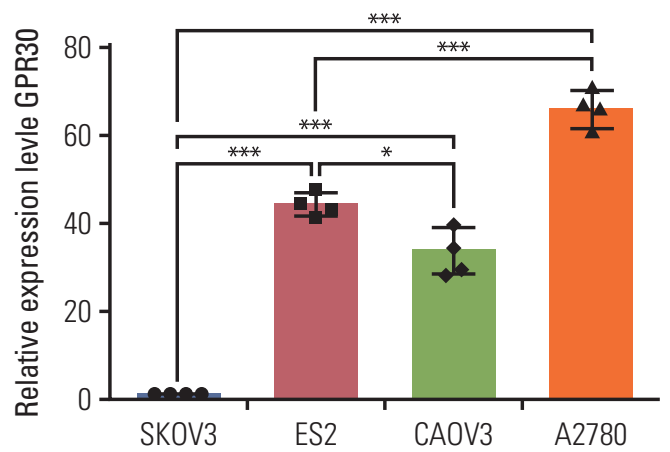

Fig. 2. (Continued from the previous page) (F) Intracellular cAMP by EPA in ES2 cells. Cells were treated with 0.1\% BSA, 300 $\mu \mathrm{M}$ PAL, or $300 \mu \mathrm{M}$ EPA for 24 hours for cAMP measurement. $(G)$ The relative expression of various GPRs in ES2 cells by RT-PCR. Data were normalized to the expression level of free fatty acid receptor 3 (FFAR3). (H) Interaction of GPR30 and EPA was detected by a protein lipid overlay assay. Increasing amounts of EPA were incubated with increasing concentrations of purified GFP-GPR30 harvested from ES2 cell lysates. (I) Relative expression of GPR30 was measured by quantitative RTPCR in different ovarian cancer cell lines. Data were normalized to the expression level in SKOV3. Values are presented as mean \pm standard deviation from three independent experiments. ${ }^{*} \mathrm{p}<0.05,{ }^{* *} \mathrm{p}<0.01,{ }^{* * *} \mathrm{p}<0.001$; ns, not significant.

cinoma in Japan, and the lethality rate of adenocarcinoma is also high [16]. Compared with other types of ovarian carcinomas, OCCCs have a poorer prognosis and are more frequently platinum resistant [17]. Here, we selected the ES2 OCCC and SKOV3 adenocarcinoma cell lines for study. ES2 and SKOV3 were first treated with several FAs at different doses for 24 hours $(0-300 \mu \mathrm{M})$. We found that palmitic acid, a saturated FA, obviously enhanced cell growth, while EPA inhibited ES2 and SKOV3 cell proliferation in a dose-dependent manner (Fig. 1A), which is in accordance with the published anticancer effects of EPA [18]. However, EPA promoted cell proliferation in CAOV3 and A2780 cell lines, indicating the antitumor effect of EPA may be cell line specific event (S4 Fig.). We also analyzed the toxicity of palmitic acid and EPA on ES2 and SKOV3 cells by using a cytotoxicity assay. We found that cell toxicity affected ES2 cells at a $400 \mu \mathrm{M}$ concentration, while the effect on SKOV3 cells was minor at 400 $\mu \mathrm{M}$ (Fig. 1B). Thus, $300 \mu \mathrm{M}$ was an appropriate concentration for use in subsequent experiments. The pro-proliferation effect of palmitic acid and the inhibitory effect of EPA on ES2 and SKOV3 cells were also time-dependent. Palmitic acid treatment increased cell growth in both ovarian cancer cell lines. However, the growth of ES2 cells was significantly decreased when treated with EPA compared to that of SKOV3 cells (Fig. 1C), suggesting that EPA had a much more pronounced effect in ES2 cells than in SKOV3 cells.

As previously reported, n-3 PUFAs (docosahexaenoic acid or EPA) inhibit colorectal cancer cell proliferation by inducing cell apoptosis [19]. Therefore, we detected cell apoptosis caused by EPA treatment in ES2 cells. The flow cytometry results showed that apoptotic cells were approximately $14.4 \%$ in EPA-treated ES2 cells, more than that in control $(0.03 \%)$. The protein expression analysis also confirmed that EPA led to cleaved caspase-3 activation (Fig. 1D). mRNA 
A

B
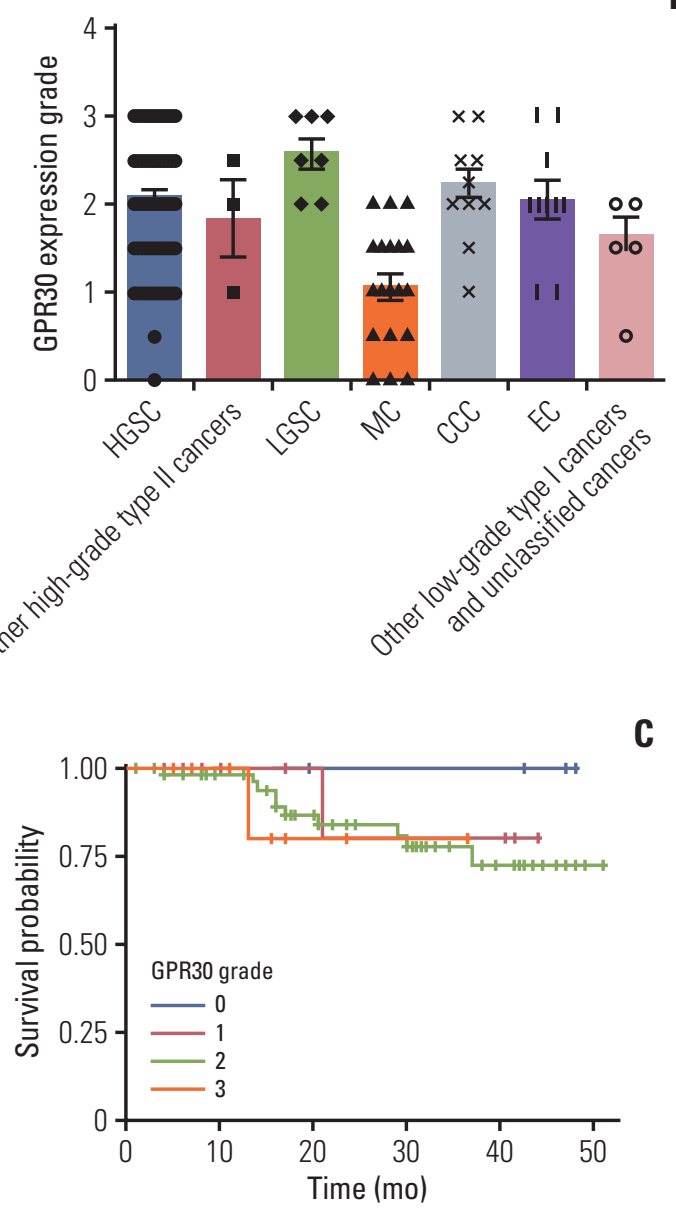

Fig. 3. G protein-coupled receptor 30 (GPR30) is expressed in patients with various ovarian cancers. The expression level of GPR30 in patients with various ovarian cancers according to a tissue microarray and immunohistochemistry. (A) Immunohistochemical staining of GPR30 in ovarian tissues with various ovarian cancers. (B) The expression grade of GPR30 in patients with various ovarian cancers ( $\mathrm{n}=173)$. HGSC, high-grade serous carcinoma; LGSC, low-grade serous carcinoma; MC, mucinous carcinoma, CCC, clear cell carcinoma; EC, endometrioid adenocarcinoma. (C) The correlation analysis of GPR30 expression level with overall survival of patients (The grade score 0 to 3 represents the intensity of GPR30 from lowest to highest).
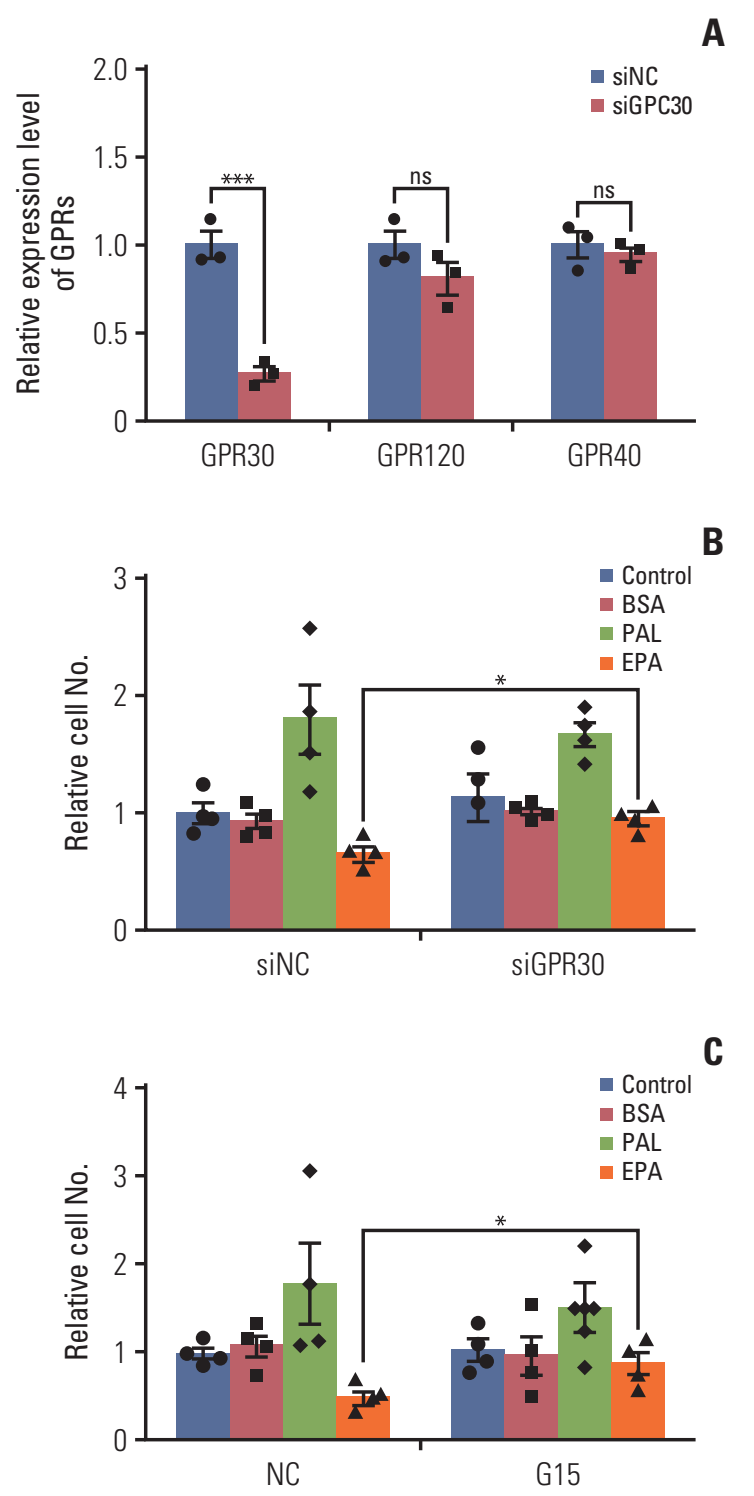

Fig. 4. G protein-coupled receptor 30 (GPR30) is involved in eicosapentaenoic acid (EPA)-induced cell antiproliferation and proapoptosis in ES2 cells. (A) The efficacy of GPR30 small interfering RNA (siRNA). (B) Cell proliferation of ES2 cells treated with $0.1 \%$ bovine serum albumin (BSA), $300 \mu \mathrm{M}$ palmitic acid (PAL), or $300 \mu \mathrm{M}$ EPA with or without GPR30 siRNA treatment. (C) Cell proliferation of ES2 cells treated with $0.1 \%$ BSA, $300 \mu \mathrm{M}$ PAL, or $300 \mu \mathrm{M}$ EPA with or without G15. (Continued to the next page)

expression analysis confirmed that EPA-induced proapoptotic genes activation and antiapoptotic genes inhibition in ES2 cells (Fig. 1E). Importantly, the cytotoxicity and apoptosis of normal ovarian epithelial cells were not affected by 300 $\mu \mathrm{M}$ EPA treatment (Fig. $1 \mathrm{~F}$ and G). Together, these data 

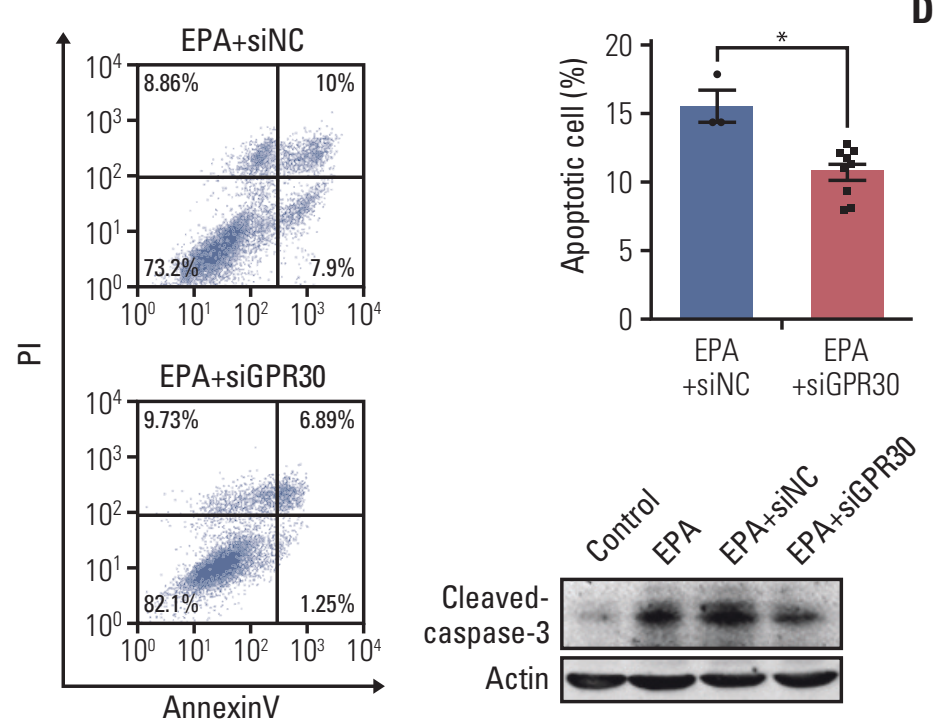

D

$\mathbf{E}$

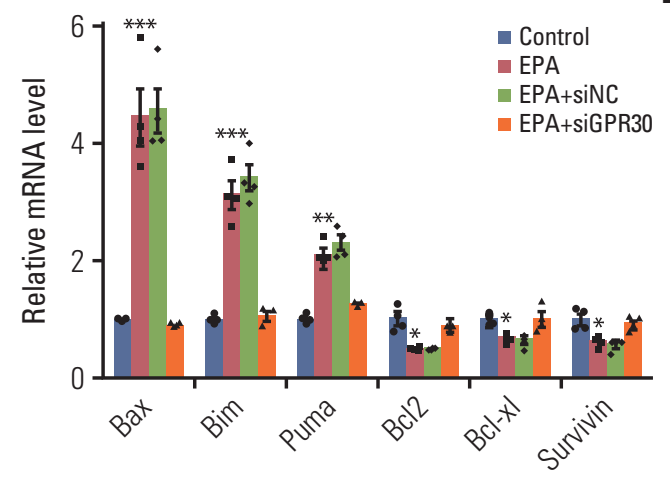

Fig. 4. (Continued from the previous page) (D) Apoptosis of ES2 cells treated with $300 \mu \mathrm{M}$ EPA and control RNA interference (RNAi) or $300 \mu \mathrm{M}$ EPA and GPR30 RNAi for 48 hours. Apoptosis was detected by cleaved caspase-3. PI, propidium iodide.

(E) The expression of proapoptotic genes and antiapoptotic genes in ES2 cells treated with $300 \mu \mathrm{M} \mathrm{EPA} \mathrm{or} 300 \mu \mathrm{M}$ EPA and GPR30 siRNA for 48 hours was analyzed by quantitative reverse transcription polymerase chain reaction. Values are presented as mean \pm standard deviation from three independent experiments. ${ }^{*} \mathrm{p}<0.05,{ }^{* *} \mathrm{p}<0.01,{ }^{* * *} \mathrm{p}<0.001$.

indicate that EPA induces ovarian cancer cell apoptosis.

\section{GPR30 acts as a novel EPA receptor in ES2 cells}

Previous findings suggest the receptors of long-chain FAs are GPR40 and GPR120 [20], and these GPR agonists could induce cell proliferation [21]. There are four subfamilies of $\alpha$ subunits of $G$ proteins: $G_{a s}, G_{a i}, G_{a q}$, and $G_{\alpha 12}$. GPR40 and GPR120 couple to the $\alpha q$ subfamily of $G$ proteins, which can be inhibited by YM254890 [10], increasing the downstream effector $\mathrm{Ca}^{2+}$ [22]. To determine whether GPR40 and GPR120 mediate the effects of palmitic acid and EPA in ES2 cells, we measured changes in $\left[\mathrm{Ca}^{2+}\right]$ in cells following palmitic acid or EPA treatments in the absence and presence of the $\mathrm{Gq}$ inhibitor YM254890, which can completely block the Gq pathways [10]. The modest increase in $\mathrm{Ca}^{2+}$ that we detected could be attributed to $\mathrm{G}_{\beta \gamma}$, which could have activated PLC $\beta$ on the cell membrane and finally cause $\mathrm{Ca}^{2+}$ release from the endoplasmic reticulum. Without YM254890 treatment, palmitic acid and EPA activated $\left[\mathrm{Ca}^{2+}\right]$ increases of 4- and 1.5-fold, respectively (Fig. 2A). Interestingly, with YM254890 treatment, the increase in $\left[\mathrm{Ca}^{2+}\right]$ by EPA did not change, while the increase in $\left[\mathrm{Ca}^{2+}\right]$ by palmitic acid was inhibited (Fig. 2B). These results indicate that palmitic acid functions mainly through the Gq pathway, while EPA might have its effects through other $G_{\alpha}$ pathways.
Similarly, we studied the effect of YM254890 on palmitic acid proliferation as well as the EPA antiproliferative effect in ES2 cells. As shown in Fig. 2C, YM254890 decreased palmitic acid-induced proliferation by 15\% (Fig. 2C). However, YM254890 did not affect EPA-induced antiproliferation or proapoptosis effects (Fig. 2C and D). Consistent with the data above, the expression of proapoptotic genes, antiapoptotic genes, and cleaved caspase-3 as influenced by EPA was not changed by YM254890 (Fig. 2E). The results above suggest that GPR40 or GPR120, whose subunit is $\mathrm{G}_{\alpha q}$, is not involved in the anticancer effect of EPA in ES2 cells. Unlike the $\mathrm{G}_{\alpha q}$ family, whose downstream effect is increasing $\left[\mathrm{Ca}^{2+}\right], \mathrm{G}_{\text {as }}$ increases but $\mathrm{G}_{\text {ai }}$ decreases the level of cAMP [22]. To identify which $\mathrm{G}_{\alpha}$ subunit functioned when ES2 cells were treated with EPA, we first measured the production of cAMP in ES2 cells treated with palmitic acid or EPA. The results showed that EPA but not palmitic acid increased cAMP compared to vehicle (Fig. 2F), suggesting that the EPA receptor is coupled to $G_{\text {as }}$ protein.

Based on the above results, we hypothesized that there exists some GPR whose $G_{\text {as }}$ subunit plays a dominant role in the EPA effect in ES2 cells. Thus, we detected various GPR proteins expression levels in ES2 cells. Quantitative PCR analysis showed that GPR30, coupled to Gus protein [23], was significantly higher than other GPRs (Fig. 2G). We also detected and graded expression of GPR30 in patients with 


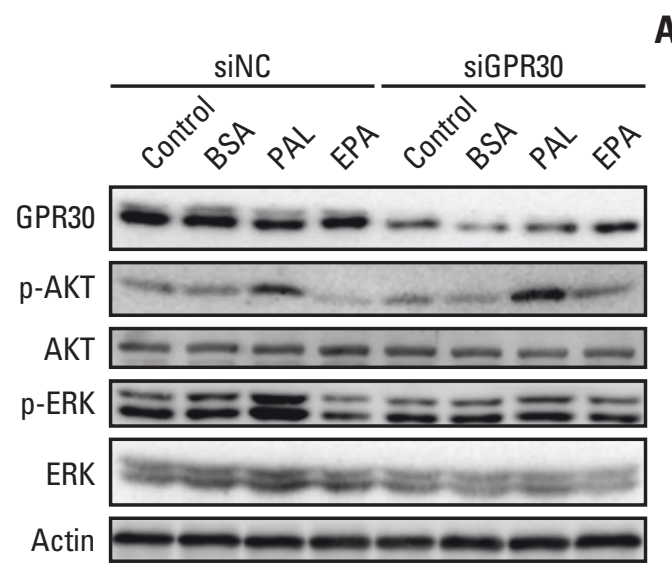

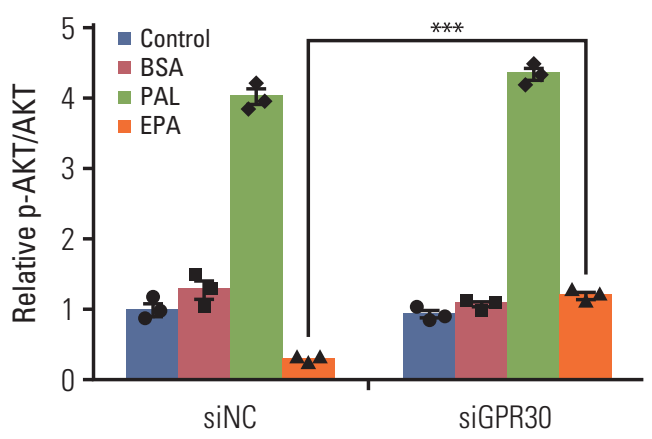

C

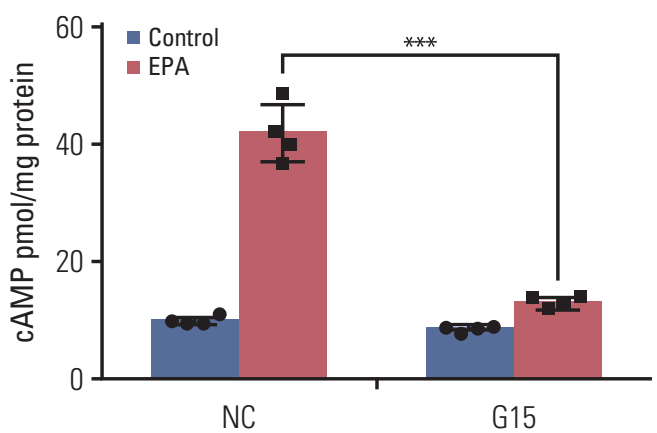

A

B

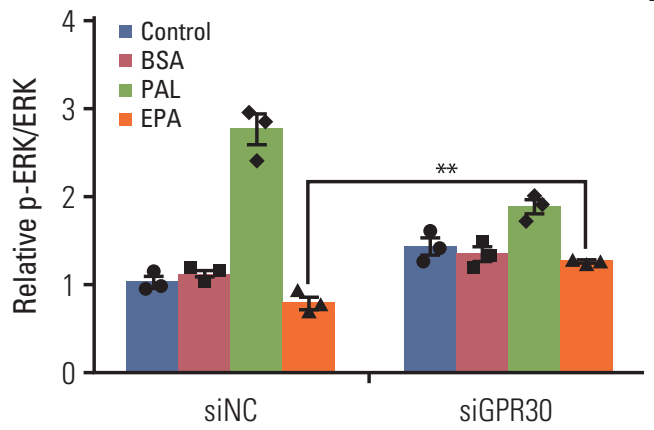

D

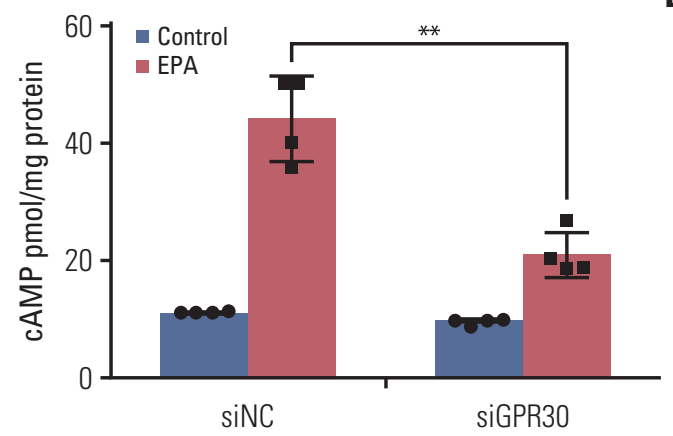

Fig. 5. Eicosapentaenoic acid (EPA) participates in the G protein-coupled receptor 30 (GPR30)-cAMP-protein kinase A signaling pathway in ES2 cells. (A) After 24 hours of serum starvation in Opti-MEM, cells were incubated for 24 hours in OptiMEM and stimulated with phosphate buffered saline alone (control), $0.1 \%$ bovine serum albumin (BSA), $300 \mu \mathrm{M}$ palmitic acid (PAL) bound to BSA $(0.1 \%)$ or $300 \mu \mathrm{M}$ EPA bound to BSA $(0.1 \%)$ with or without GPR30 siRNA treatment. (B) pAKT / AKT and p-ERK/ ERK were analyzed by Western blotting and quantified by ImageJ. (C, D) ES2 cells were treated with or without $300 \mu \mathrm{M}$ EPA in the absence and presence of G15 (C) or GPR30 siRNA (D) for 24 hours for cAMP measurement. (Continued to the next page)

various ovarian cancer, including high-grade serous carcinomas, low-grade serous carcinomas (LGSC), mucinous carcinomas (MC), clear cell carcinomas (CCC), and endometrioid adenocarcinoma. The immunohistochemistry results showed that GPR30 was widely expressed in patients with various ovarian cancers, highly in LGSC while lowly in MC (Fig. 3A and B). Furthermore, the correlation analysis of GPR30 expression level with overall survival of ovarian cancers patients showed that patients with higher GPR30 expression level (grade 3) showed shorter survival time, while patients 

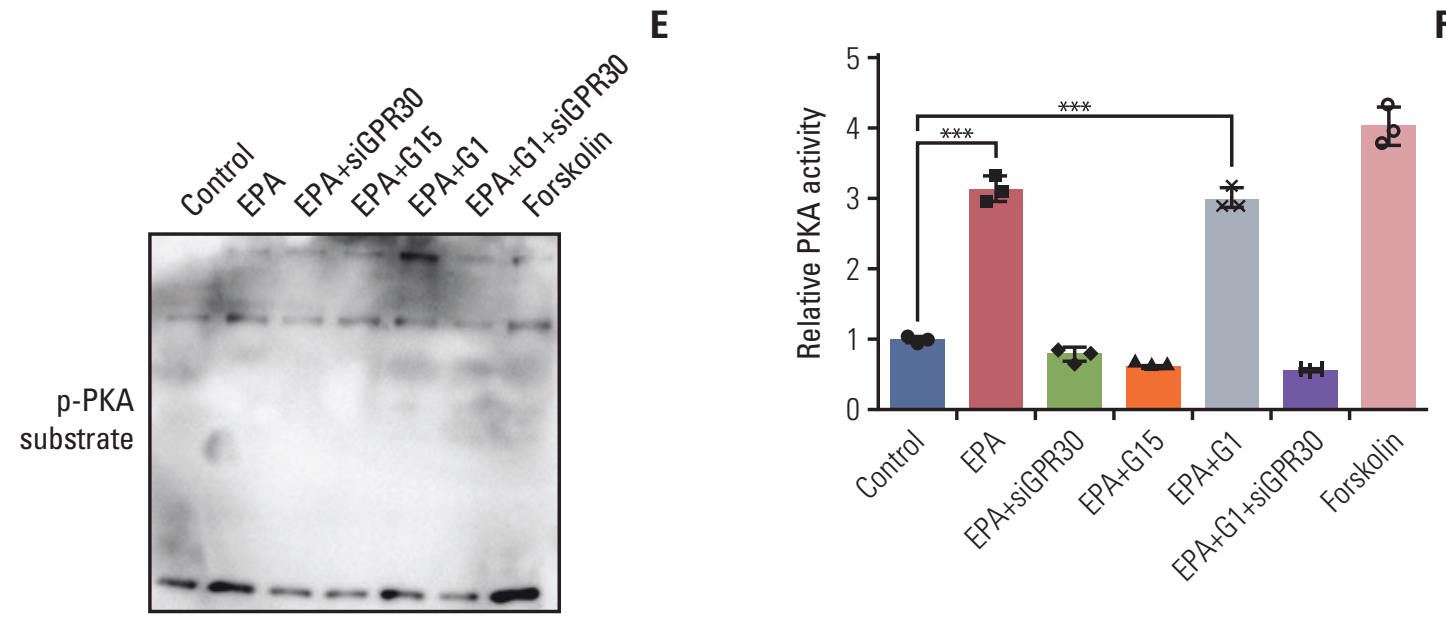

Fig. 5. (Continued from the previous page) (E) Phospho-(Ser/Thr) substrate was detected by Western blotting in ES2 cells treated with EPA, EPA+GPR30 siRNA, EPA+G15, EPA+G1 (500 nM, the specific agonist of GPR30) or EPA+G1+GPR30 siRNA. (F) PKA activities were quantified by ImageJ, and the data are expressed as PKA activity $(n=3)$. Values are presented as mean \pm standard deviation from three independent experiments. ${ }^{* *} \mathrm{p}<0.01,{ }^{* * *} \mathrm{p}<0.001$.

with lower GPR30 expression level (grade 0 ) showed longer survival time (Fig. 3C, S1-S3 Table).To further verify whether EPA was a ligand of GPR30 in ES2 cells, we used a modified protein lipid overlay assay [14]. As shown in Fig. 2H, the interaction between EPA and GPR30 existed and was dosedependent. Moreover, the relative expression level of GPR30 was markedly lower in SKOV3 cells compared with ES2 cells, A2780 cells, and CAOV3 cells, indicating that GPR30 functions differently in different cell lines (Fig. 2I).

\section{GPR30 mediates the EPA effect in ES2 cells}

To determine whether GPR30 mediates the effect of EPA in ES2 cells, we knocked down GPR30 using RNAi and found that GPR30 expression was reduced by $80 \%$ without changes in GPR40 or GPR120 (Fig. 4A). The decrease in cell number following EPA treatment was significantly reversed in ES2 cells treated with GPR30-specific siRNA (Fig. 4B). Similarly, we used G15, the specific antagonist of GPR30, to test the EPA effect in ES2 cells. As shown in Fig. 4C, the inhibitory effect of EPA was again impaired. The siRNA and inhibitor results indicated that EPA-induced antiproliferation in ES2 cells is mediated through GPR30.

Furthermore, we knocked down GPR30 to examine its effect on the EPA proapoptotic action in ES2 cells. The number of apoptotic cells dramatically declined when ES2 cells were treated with GPR30 siRNA compared with negativecontrol siRNA (Fig. 4D). Additionally, the expression of apoptotic genes as influenced by EPA was reversed when GPR30 was knocked down (Fig. 4D and E). However, the proapoptotic effect of EPA on ES2 cells could not be reversed when GPR119 was knocked down (S5 Fig.), indicating GPR119, another $\mathrm{G}_{\mathrm{as}}$ coupled receptor, did not play an essential role in mediating the anticancer effect of EPA in ES2 cells. Altogether, the above results establish that GPR30 is essential in mediating the effect of EPA in ES2 cells.

\section{EPA inhibits cell proliferation through the GPR30- cAMP-PKA signaling pathway in ES2 cells}

The phosphoinositide 3-kinase (PI3K)/AKT signaling pathway is the most common pathway related to cancer proliferation [24]. In recent years, numerous reports have demonstrated that EPA is implicated in several signaling pathways, such as RAS/ERK / C /EBP $\beta$ and nuclear factor $\mathrm{KB}$, contributing to tumor development and inflammation [25]. To evaluate whether EPA affects cell proliferation through these cellular response pathways, we investigated phosphorylated AKT and ERK1/ 2 in ES2 cells treated with or without EPA. Interestingly, palmitic acid stimulated AKT and ERK1/2 phosphorylation, while EPA inhibited their phosphorylation after 24 hours of treatment (Fig. 5A). To further determine whether GPR30 was involved in the activation of AKT and ERK1/2, we knocked down GPR30 as mentioned above. The phosphorylation levels of AKT and ERK1/2 in response to palmitic acid did not obviously change, and that in response to EPA was dramatically increased when ES2 cells were treated with GPR30 siRNA (Fig. 5A and B). These findings suggest that the development of signaling pathways via GPR30 includes PI3K-AKT and ERK. 
A
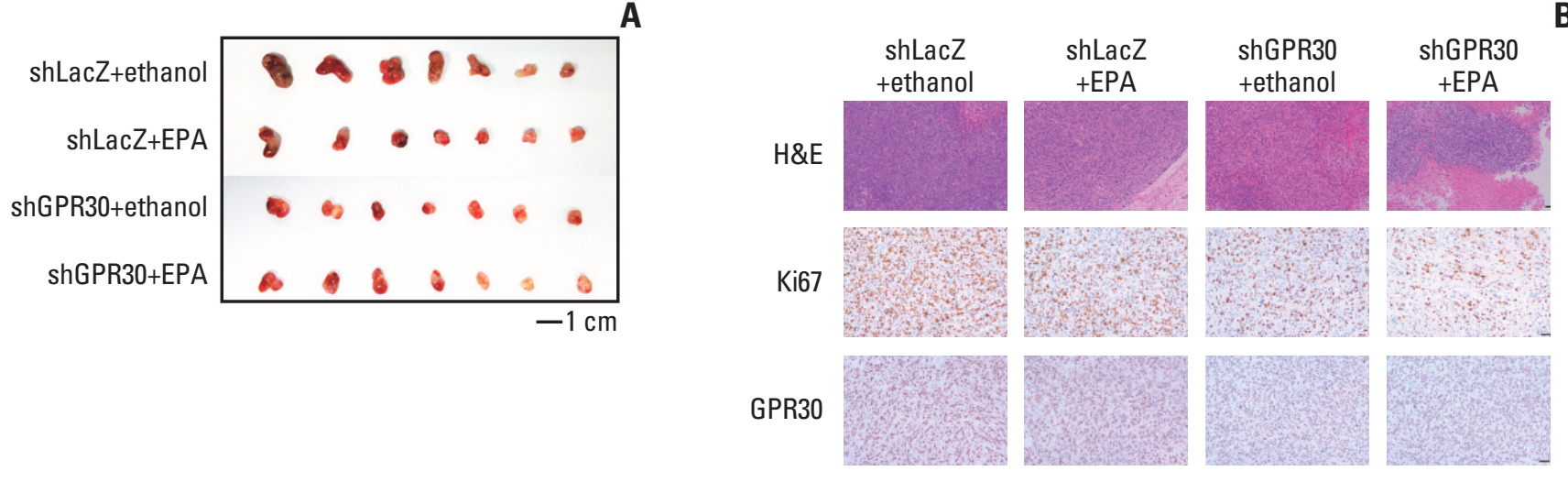

B

C
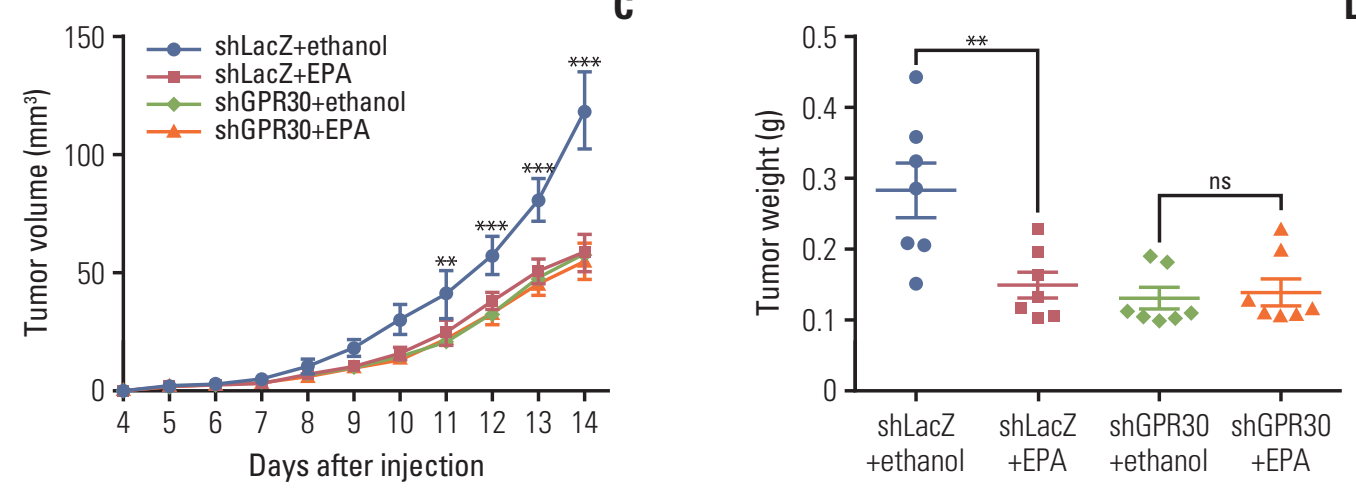

D

E
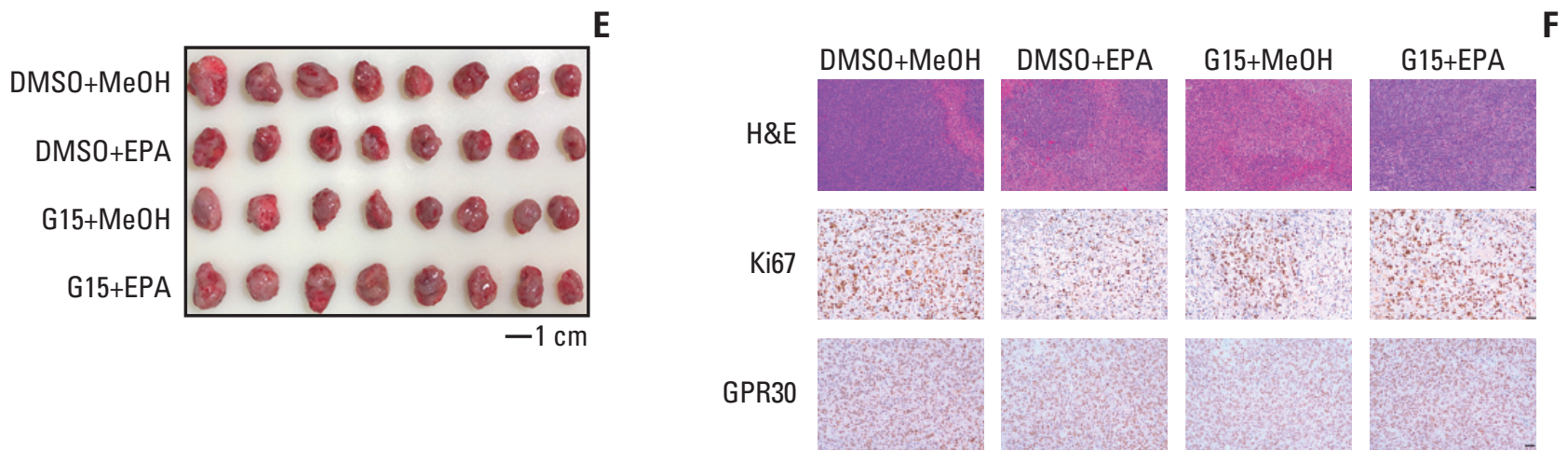

Fig. 6. Eicosapentaenoic acid (EPA) blocks tumor growth via G protein-coupled receptor 30 (GPR30) in mouse xenografts. (A, B) Nude mice bearing ovarian tumors (ES2 cells) were received ethanol in combination with LacZ shRNA as a control, EPA in combination with LacZ shRNA, ethanol in combination with GPR30 shRNA or EPA in combination with GPR30 shRNA. (A) Xenograft tumors (scale bar=1 cm). (B) Ki67 and GPR30 expression (scale bar=50 $\mu \mathrm{m}$ ). Tumor volume (C) and tumor weight (D) in (A). (E, F) Nude mice bearing ovarian tumors (ES2 cells) were received dimethyl sulfoxide (DMSO) in combination with $\mathrm{MeOH}$ as a control, EPA in combination with DMSO, MeOH in combination with G15 or EPA in combination with G15. (E) Xenograft tumors (scale bar=1 cm). (F) Ki67 and GPR30 expression (scale bar=50 $\mu \mathrm{m}$ ). (Continued to the next page)

The results in Figs. 2 and 4 show that EPA inhibits ES2 cell growth through GPR30. Due to the inhibitory effect on cancer cell growth by $\mathrm{G}_{a s}$-cAMP-PKA signaling activation [26], the $\mathrm{G}_{\text {as }}$-CAMP-PKA signaling pathway may be affected by
EPA via GPR30 in ES2 cells. Thus, we knocked down GPR30 in ES2 cells by GPR30 siRNA and G15 as described above. The cAMP production promoted by EPA was attenuated following downregulation of GPR30 (Fig. 5C and D). Addition- 

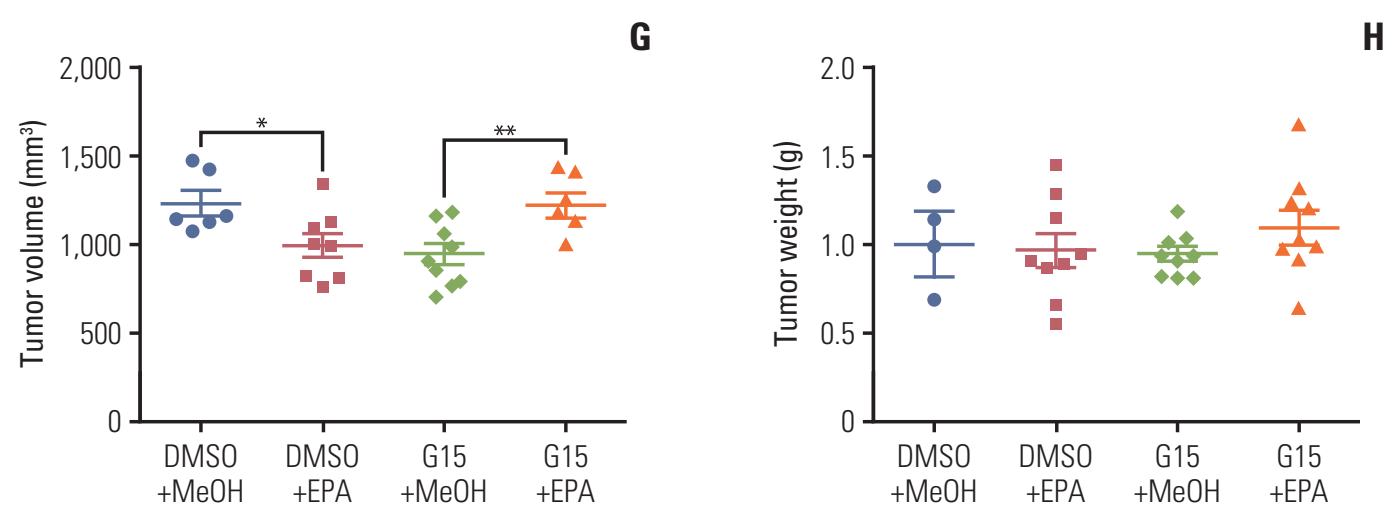

Fig. 6. (Continued from the previous page) Tumor volume $(\mathrm{G})$ and tumor weight $(\mathrm{H})$ in $(\mathrm{E})$. Values are presented as mean \pm standard deviation from three independent experiments. ${ }^{*} \mathrm{p}<0.05,{ }^{* *} \mathrm{p}<0.01,{ }^{* * *} \mathrm{p}<0.001$.

ally, EPA increased PKA activity compared to the treatment vehicle, as detected by the phospho-(Ser/Thr) PKA substrates. Notably, G1, the specific agonist of GPR30, also increased PKA activity. Moreover, PKA activity stimulated by EPA was suppressed by GPR30 knockdown and G15. However, PKA activity stimulated by EPA, G1, and siGPR30 did not change compared to its activity stimulated by EPA and siGPR30 (Fig. 5E and F). These results indicate that GPR30-cAMP-PKA signaling is involved in the EPA effect in ES2 cells.

\section{EPA blocks tumor growth via GPR30 in mouse xeno- grafts}

To confirm the above observations, we also conducted a mouse xenograft model to further verify the role of GPR30 in ES2 cells. In accordance with previous findings, EPA alone inhibited tumor growth significantly (Fig. 6A and E). To further confirm the function of GPR30, we knocked down GPR30 using adenovirus in a mouse xenograft model. As shown in Fig. 6A, EPA dramatically decreased tumor growth, while EPA was unable to inhibit tumor growth when GPR30 was knocked down. hematoxylin and eosin (H\&E) staining and labeling for the cancer proliferation marker Ki67 also showed that EPA lost its inhibitory function when ES2 cells were treated with GPR30 shRNA (Fig. 6B). The change in tumor volume and weight supported the above results (Fig. 6C and D). Interestingly, we found that the deletion of GPR30 in ES2 cells decreased tumor growth in mice, suggesting that GPR30 is associated with tumor development. Therefore, we antagonized GPR30 activity by treatment with GPR30 antagonist G15 in the mouse xenograft model. Although the tumor weight had no significant change due to individual variation (Fig. $6 \mathrm{H}$ ), the tumor size and $\mathrm{H} \& \mathrm{E}$ staining showed that EPA or G15 alone both inhibited cell proliferation significantly (Fig. 6E-G). The combination of EPA and G15 was unable to inhibit tumor growth, as G15 inhibited antitumor effect of EPA by impairing GPR30 activity. These in vivo results also suggest that EPA inhibits tumor growth via GPR30 in human ovarian clear cancer cells.

\section{Discussion}

Extensive research implies that dysregulation of lipid metabolism is correlated with ovarian cancer progression [27]. EPA, an n-3 polyunsaturated FA, has anticancer effects in many cancer cells, such as colorectal cancer [28], breast cancer [3], pancreatic cancer [28], and ovarian cancer [5]. In our study, EPA-induced apoptosis in ES2 OCCC cells following induction of antiproliferation through GPR30, a novel EPA receptor. Additionally, EPA stimulated the activation of caspase-3, blunted the activation of AKT and ERK1/2 and functioned through the GPR30-cAMP-PKA signaling pathway.

Classical free fatty acid receptors, such as GPR40, and GPR120, might also mediate the function of EPA in ovarian cancer cells. Since Gaq is the $\alpha$ subunit of both GPR40 and GPR120, whose activation leads to a rapid increase in $\mathrm{Ca}^{2+}$, we detected the $\mathrm{Ca}^{2+}$ concentration after adding EPA, and an approximately 1.5-fold increase was observed. Importantly, YM254890, a specific inhibitor of the Gaq unit, did not inhibit the increase in $\mathrm{Ca}^{2+}$ caused by EPA, suggesting that neither GPR40 nor GPR120 is the specific receptor of EPA. We found a novel EPA receptor, GPR30, in ovarian cancer cells, confirmed by a modified protein lipid assay [14], thus broadening the concept of cancer metabolism. GPR30, which was once thought to be an orphan receptor, has been implicated 
in both rapid and transcriptional events in response to estrogen. Ligands of GPR30 are mainly steroids and some synthetic estrogen-receptor ligands, and the pro-proliferation effects of E2 in hormone-related tumors are well known. When we blocked GPR30 expression by shRNA in vivo, we also blocked the pro-proliferation effects of $\mathrm{E} 2$ because of the lack of ER $\alpha$ and ER $\beta$ in ES2 cells. Therefore, the volume and weight of these tumors were significantly decreased, as shown in Fig. 6D. Above all, we first proved that besides steroids, EPA is also a ligand for GPR30.

Oxidative stress has been reported to affect cancer cell development. For example, reactive oxygen species (ROS) participate in cancer cell progression and proliferation, cell apoptosis, and energy metabolism [29]. Previous reports showed that EPA mainly causes ROS-induced apoptosis [28]. The cell death, which mainly occurs in the late apoptosis phase, is due to the intracellular ROS-induced caspase-8 activation [30]. Other evidence has demonstrated that EPA also induces autophagic cell death [28]. Here, we show that EPA increased the activation of caspase- 3 and stimulated the expression of apoptotic genes. We found that EPA promoted a less antiproliferative signal in ES2 cells but an insensitive response in SKOV3 cells treated with GPR30 siRNA. Considering that different types of ovarian cancer have distinctive morphologic and molecular-genetic features, GPR30 may be coupled to G proteins more tightly in ES2 cells than in SKOV3 cells. Another reason may be that the enrichment of GPR30 protein varies between ovarian cancer cells and that SKOV3 cells have a low expression level of GPR30 (Fig. 2I). Besides, EPA exists pro-proliferation effect on CAOV3 and A2780 cell lines, indicating the antitumor effect of EPA may be cell-line specific event. Therefore, further investigation about the effect of EPA on other CCC cells should be required.

Our observations suggest that in ES2 OCCC cells, EPA functions through the GPR30- $\mathrm{G}_{\text {ss }}$-CAMP-PKA signaling pathway. Originally, phosphorylation of ERK1/ 2 is increased by $\mathrm{G}_{\beta \gamma}$, which is dissociated from $\mathrm{G} \alpha$. Previous work also demonstrated that PKA stimulated by the $\alpha$ subunit of GPR30 could decrease the phosphorylation of ERK1/2 [26]. We think that crosstalk between them may account for the decreased phosphorylation level in our study. Further investigation will elucidate the specific functions of signaling pathways activated by EPA, including autophagy, metabolism, cell cycle.

Overall, our study provides evidence that GPR 30 is a novel receptor of EPA in ES2 cells that mediates its anticancer effects. EPA might inhibit proliferation by inducing apoptosis. Additionally, EPA might influence the GPR30-ERK or GPR30-AKT signaling pathway. In our future work, we will examine the mechanism of the effects that EPA has on other backgrounds. In addition, because other researchers have provided evidence that EPA can improve the sensitivity to chemotherapy [2], we wondered whether EPA could improve the chemotherapy resistance of OCCC through GPR30. Answering these questions could provide a theoretical basis for the clinical treatment of OCCC.

\section{Electronic Supplementary Material}

Supplementary materials are available at Cancer Research and Treatment website (https://www.e-crt.org).

\section{Conflicts of Interest}

Conflict of interest relevant to this article was not reported.

\section{Acknowledgments}

We thank Prof. Zhongren Ding from Shanghai Medical College of Fudan University for kindly providing YM254890 from Yamanouchi Pharmaceutical Co., Ltd. (Ibaraki, Japan). This work was supported by the Chinese National Science Foundation (31601153 to Y.Z., 81770861 and 31571401 to X. Li), the Nature Science Foundation of Jiangsu Province (BK20160619 to Y.Z.), the Social Development Fund of Jiangsu Province (BE2017708 to C.L.), the Fundamental Research Funds for the Central Universities (14380269, 14380343,14380469 to Y.Z.), and by China Postdoctoral Science Foundation (2016M601778 to Y.Z.). Chong Qing Science and Technology Foundation (cstc2018jcyjAX0232 to X. Li), Chong Qing Education Foundation (KJZD-K201800402 to X. Li).

\section{Author Details}

${ }^{1}$ State Key Laboratory of Pharmaceutical Biotechnology and Jiangsu Key Laboratory of Molecular Medicine, Medical School of Nanjing University, Nanjing, '2Department of Obstetrics and Gynecology, Xiamen Chang Gung Hospital, Xiamen, ${ }^{3}$ Obstetrics and Gynecology Hospital, Fudan University, Shanghai, ${ }^{4}$ Department of Pathology, Nanjing Drum Tower Hospital, The Affiliated Hospital of Nanjing University Medical School, Nanjing, ${ }^{5}$ Biology Science Institutes, Chongqing Medical University, Yuzhong, China 


\section{References}

1. Sapienza C, Issa JP. Diet, nutrition, and cancer epigenetics. Annu Rev Nutr. 2016;36:665-81.

2. Rose DP, Connolly JM. Omega-3 fatty acids as cancer chemopreventive agents. Pharmacol Ther. 1999;83:217-44.

3. Velentzis LS, Keshtgar MR, Woodside JV, Leathem AJ, Titcomb A, Perkins KA, et al. Significant changes in dietary intake and supplement use after breast cancer diagnosis in a UK multicentre study. Breast Cancer Res Treat. 2011;128:47382.

4. Jemal A, Siegel R, Xu J, Ward E. Cancer statistics, 2010. CA Cancer J Clin. 2010;60:277-300.

5. Brinton EA, Mason RP. Prescription omega-3 fatty acid products containing highly purified eicosapentaenoic acid (EPA). Lipids Health Dis. 2017;16:23.

6. Santos CR, Schulze A. Lipid metabolism in cancer. FEBS J. 2012;279:2610-23.

7. Maggiolini M, Picard D. The unfolding stories of GPR30, a new membrane-bound estrogen receptor. J Endocrinol. 2010; 204:105-14.

8. Heublein S, Mayr D, Friese K, Jarrin-Franco MC, Lenhard M, Mayerhofer A, et al. The G-protein-coupled estrogen receptor (GPER/GPR30) in ovarian granulosa cell tumors. Int J Mol Sci. 2014;15:15161-72.

9. Mazzuca MQ, Mata KM, Li W, Rangan SS, Khalil RA. Estrogen receptor subtypes mediate distinct microvascular dilation and reduction in $[\mathrm{Ca} 2+] \mathrm{I}$ in mesenteric microvessels of female rat. J Pharmacol Exp Ther. 2015;352:291-304.

10. Jin J, Mao Y, Thomas D, Kim S, Daniel JL, Kunapuli SP. RhoA downstream of $\mathrm{G}(\mathrm{q})$ and $\mathrm{G}(12 / 13)$ pathways regulates protease-activated receptor-mediated dense granule release in platelets. Biochem Pharmacol. 2009;77:835-44.

11. Taniguchi M, Nagai K, Arao N, Kawasaki T, Saito T, Moritani Y, et al. YM-254890, a novel platelet aggregation inhibitor produced by Chromobacterium sp. QS3666. J Antibiot (Tokyo). 2003;56:358-63.

12. Wang C, Lv X, Jiang C, Davis JS. The putative G-protein coupled estrogen receptor agonist G-1 suppresses proliferation of ovarian and breast cancer cells in a GPER-independent manner. Am J Transl Res. 2012;4:390-402.

13. Bai LY, Weng JR, Hu JL, Wang D, Sargeant AM, Chiu CF. G15, a GPR30 antagonist, induces apoptosis and autophagy in human oral squamous carcinoma cells. Chem Biol Interact. 2013;206:375-84.

14. Pal D, Dasgupta S, Kundu R, Maitra S, Das G, Mukhopadhyay $\mathrm{S}$, et al. Fetuin-A acts as an endogenous ligand of TLR4 to promote lipid-induced insulin resistance. Nat Med. 2012;18:127985.

15. Hu L, Lau SH, Tzang CH, Wen JM, Wang W, Xie D, et al. Association of Vimentin overexpression and hepatocellular carcinoma metastasis. Oncogene. 2004;23:298-302.

16. Sugiyama T, Kamura T, Kigawa J, Terakawa N, Kikuchi Y, Kita T, et al. Clinical characteristics of clear cell carcinoma of the ovary: a distinct histologic type with poor prognosis and resistance to platinum-based chemotherapy. Cancer. 2000;88: 2584-9.

17. Landrum LM, Java J, Mathews CA, Lanneau GS Jr, Copeland LJ, Armstrong DK, et al. Prognostic factors for stage III epithelial ovarian cancer treated with intraperitoneal chemotherapy: a Gynecologic Oncology Group study. Gynecol Oncol. 2013; 130:12-8.

18. Kwan HY, Fu X, Liu B, Chao X, Chan CL, Cao H, et al. Subcutaneous adipocytes promote melanoma cell growth by activating the Akt signaling pathway: role of palmitic acid. J Biol Chem. 2014;289:30525-37.

19. Sun H, Hu Y, Gu Z, Owens RT, Chen YQ, Edwards IJ. Omega3 fatty acids induce apoptosis in human breast cancer cells and mouse mammary tissue through syndecan- 1 inhibition of the MEK-Erk pathway. Carcinogenesis. 2011;32:1518-24.

20. Kotarsky K, Nilsson NE, Flodgren E, Owman C, Olde B. A human cell surface receptor activated by free fatty acids and thiazolidinedione drugs. Biochem Biophys Res Commun. 2003;301:406-10.

21. Gu Z, Suburu J, Chen H, Chen YQ. Mechanisms of omega-3 polyunsaturated fatty acids in prostate cancer prevention. Biomed Res Int. 2013;2013:824563.

22. Dorsam RT, Gutkind JS. G-protein-coupled receptors and cancer. Nat Rev Cancer. 2007;7:79-94.

23. Prossnitz ER, Oprea TI, Sklar LA, Arterburn JB. The ins and outs of GPR30: a transmembrane estrogen receptor. J Steroid Biochem Mol Biol. 2008;109: 350-3.

24. Shu YJ, Weng H, Ye YY, Hu YP, Bao RF, Cao Y, et al. SPOCK1 as a potential cancer prognostic marker promotes the proliferation and metastasis of gallbladder cancer cells by activating the PI3K/ AKT pathway. Mol Cancer. 2015;14:12.

25. Brazil DP, Yang ZZ, Hemmings BA. Advances in protein kinase B signalling: AKTion on multiple fronts. Trends Biochem Sci. 2004;29:233-42.

26. Castoria G, Migliaccio A, D'Amato L, Di Stasio R, Ciociola A, Lombardi $\mathrm{M}$, et al. Integrating signals between cAMP and MAPK pathways in breast cancer. Front Biosci. 2008;13:131827.

27. Nieman KM, Kenny HA, Penicka CV, Ladanyi A, Buell-Gutbrod R, Zillhardt MR, et al. Adipocytes promote ovarian cancer metastasis and provide energy for rapid tumor growth. Nat Med. 2011;17:1498-503.

28. Fukui M, Kang KS, Okada K, Zhu BT. EPA, an omega-3 fatty acid, induces apoptosis in human pancreatic cancer cells: role of ROS accumulation, caspase- 8 activation, and autophagy induction. J Cell Biochem. 2013;114:192-203.

29. Sabharwal SS, Schumacker PT. Mitochondrial ROS in cancer: initiators, amplifiers or an Achilles' heel? Nat Rev Cancer. 2014;14:709-21.

30. Gajate C, Gonzalez-Camacho F, Mollinedo F. Lipid raft connection between extrinsic and intrinsic apoptotic pathways. Biochem Biophys Res Commun. 2009;380:780-4. 